\title{
Avaliação Microbiológica de Feijão-Caupi (Vigna unguiculata L.) Imaturo Sob Diferentes Tratamentos Pós-Colheita
}

\section{Microbiological Evaluation of Immature Caupi Beans Under Different Post-Harvest Treatments}

\author{
Caíke de Sousa Pereira*a; Victor Virginio de Sousa e Silva ${ }^{\text {b }}$ Jardel Alves da Costac; Renato Santos Rocha ${ }^{\text {b; }}$ Wagner \\ Rogério Leocádio Soares Pessoa ${ }^{\mathrm{b}}$; João Victor da Silva Martins ${ }^{\mathrm{a}}$
}

\author{
${ }^{\text {a} U n i v e r s i d a d e ~ F e d e r a l ~ d a ~ P a r a i ́ b a, ~ P r o g r a m a ~ d e ~ P o ́ s-G r a d u a c ̧ a ̃ o ~ S t r i c t o ~ S e n s u ~ e m ~ A g r o n o m i a . ~ P B, ~ B r a s i l . ~}$

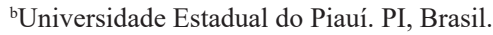 \\ 'Universidade Federal do Piauí. PI, Brasil. \\ *E-mail: cksousa7@gmail.com
}

\begin{abstract}
Resumo
A valorização de vegetais frescos, como o feijão-caupi imaturo, tem demonstrado um crescimento nos últimos anos, favorecendo o aumento gradativo na aquisição destes produtos pelos consumidores. No entanto, tais alimentos não são livres de micro-organismos, sendo necessários processos que priorizem a segurança microbiológica e o controle restrito da temperatura. Diante do exposto, objetivou-se com este trabalho avaliar a ação de diferentes tratamentos pós-colheita e tempo de armazenagem sobre os micro-organismos presentes em grãos imaturos de feijão-caupi da variedade sempre-verde. Sendo os tratamentos: T1 acondicionamento em embalagem (testemunha); T2 acondicionamento em embalagem + refrigeração; T3 condicionamento em embalagem + vácuo + refrigeração; T4 acondicionamento em embalagem + branqueamento + refrigeração; T5 acondicionamento em embalagem + branqueamento + vácuo + refrigeração. Realizaram-se as análises microbiológicas aos 10, 20 e 40 dias de armazenamento, em que para cada época, quatro repetições foram aleatoriamente amostradas e avaliadas, por tratamento, e os resultados obtidos foram expressos sob a forma de tabela. Foram realizadas as observações da incidência de bactérias, e a identificação de fungos via microscópio óptico comum. Conforme os resultados. o pré-tratamento de branqueamento em T4 e T5 apresenta uma maior redução da diversidade de micro-organismos nos grãos imaturos de feijão-caupi após armazenagem, no entanto, não é capaz de eliminar completamente fungos produtores de micotoxinas e bactérias.
\end{abstract}

Palavras-chave: Feijão-Verde. Conservação Alimentar. Segurança Alimentar.

\begin{abstract}
The appreciation of fresh vegetables, such as immature cowpea, has shown a growth in recent years, favoring the gradual increase in the purchase of these products by consumers. However, such food is not free of microorganisms, requiring processes that prioritize microbiological safety and restricted temperature control. Given the above, the objective of this work was to evaluate the action of different post-harvest treatments and storage time on microorganisms present in immature cowpea grains of the evergreen variety. The treatments: T1 packaging in packaging (control); $T 2$ packaging in packaging + refrigeration; T3 packaging conditioning + vacuum + refrigeration; T4 packaging in packaging + bleaching + refrigeration; T5 packaging in packaging + bleaching + vacuum + refrigeration. Microbiological analyzes were performed at, 10, 20 and 40 days of storage, where for each season, four replications were randomly sampled and evaluated, per treatment, and the results obtained were expressed in the form of a table. Observations of bacteria incidence were carried out, as well as the fungi identification using a standard optical microscope. According to the results, the bleaching pretreatment in T4 and T5 presents a greater reduction in the diversity of microorganisms in immature cowpea grains after storage, however, it it is not able to completely eliminate mycotoxin-producing fungi and bacteria.
\end{abstract}

Keywords: Green Beans. Food Conservation. Food Security.

\section{Introdução}

O feijão-caupi (Vigna unguiculata (L.) Walp) é considerado o segundo tipo de feijão mais cultivado no Brasil, atrás apenas do feijão comum (Phaseulus vulgaris L.), sendo de grande importância para os produtores que cultivam pequenas áreas das regiões Norte e Nordeste do país, nas quais a cultura se apresenta em elevada expansão (CONAB, 2019). Sendo que a região Nordeste se caracteriza por apresentar em sua grande maioria uma agricultura de base familiar, em que parte da produção é destinada ao consumo e o excedente comercializado (SANTOS; LIMA, 2015).

O mercado de feijão-caupi está baseado, principalmente, na produção de grãos secos ou imaturos, em que neste último caso, os grãos exibem cerca de 60 a $70 \%$ de umidade no momento da colheita, quando param de acumular fotossintatos e iniciam o processo natural de desidratação (MELO et al., 2017). Nesse sentido, Penha Filho et al. (2017) destacam que a demanda para grãos secos vem diminuído, e o que historicamente foi a principal finalidade da produção vem perdendo espaço para o mercado ascendente de vagens e grãos verdes.

Segundo Oliveira e Santos (2015), a valorização de vegetais frescos, como o feijão imaturo, tem demonstrado um crescimento nos últimos anos, favorecendo o aumento gradativo na aquisição destes produtos pelos consumidores, garantindo maior rentabilidade para os agricultores. Como 
reflexo destas mudanças na demanda por estes alimentos, novas possibilidades vêm surgindo no que diz respeito à produção de alimentos prontos para o preparo ou consumo (NESPOLO et al., 2015).

Entretanto, tais alimentos não estão livres da ação de microorganismos e, para que ocorra uma redução significativa da carga microbiana, são necessários processos que priorizem a segurança microbiológica e o controle restrito da temperatura, desde o processamento até o consumo final (FERREIRA et al., 2016). Para tanto, já foram desenvolvidas diversas tecnologias destinadas à conservação de produtos agrícolas frescos póscolheita, tais como os métodos físicos: tratamento térmico (aquecimento), refrigeração e atmosfera modificada (DE LA VEJA; CAÑAREJO; PINTO, 2017).

As altas temperaturas contribuem para a redução da carga microbiana, enquanto temperaturas mais baixas provocam inibição no desenvolvimento destes micro-organismos fitopatogênicos e deteriorantes (ROCHA et al., 2014). Nos sistemas refrigerados, a utilização de embalagem a vácuo também pode ser considerada uma alternativa eficiente ao armazenamento de hortaliças frescas, acarretando uma redução nos níveis de oxigênio disponibilizado dentro da embalagem e a troca gasosa entre o produto e o ambiente (LIMA; TOMÉ; ABREU, 2014).

No entanto, para tais técnicas e/ou métodos não ocorre esterilização do produto, havendo apenas redução moderada da flora microbiana presente, sendo exigido um processo rigoroso de refrigeração, para que se possa evitar o desenvolvimento de micro-organismos patogênicos e deterioradores (RINALDI; VIEIRA; FIALHO, 2015).

Diante do exposto, objetivou-se com este trabalho avaliar a ação de diferentes tratamentos pós-colheita e tempo de armazenagem sobre os micro-organismos presentes em amostras de grãos imaturos de feijão-caupi da variedade sempre-verde.

\section{Material e Métodos}

O trabalho foi realizado nos laboratórios de Agronomia e Biologia, da Universidade Estadual do Piauí - UESPI, em Picos, Piauí. Os grãos de feijão-caupi da variedade sempreverde foram obtidos em feiras livres do município de Picos, PI. Sendo o estádio fisiológico adequado de colheita, entre 60 a $70 \%$ de umidade de acordo com recomendações de Mendonça et al. (2015), portanto recém debulhados "frescos". Os grãos foram acondicionados em embalagem isotérmica e transportados até o laboratório da Instituição.

No laboratório foi realizada a seleção dos grãos em função do tamanho, da cor e da ausência de danos físicos. Após essa etapa, o feijão foi lavado em água corrente para retirada das sujidades e, em seguida, posto em bancadas de mármore previamente higienizadas e cobertas com papel toalha para eliminar o excesso de água sobre o tegumento. A temperatura ambiente era de $28 \pm 2{ }^{\circ} \mathrm{C}$ e umidade relativa do ar $45 \pm 5 \%$ UR e todas as atividades realizadas segundo as Boas Práticas de Fabricação (BPF), com os devidos cuidados de higienização.

Posteriormente, foram formadas porções de $100 \mathrm{~g}$ de grãos, totalizando em 80 amostras, as quais foram submetidas aos seguintes tratamentos: T1 acondicionamento em embalagem (testemunha); T2 acondicionamento em embalagem + refrigeração; T3 acondicionamento em embalagem + vácuo + refrigeração; T4 acondicionamento em embalagem + branqueamento + refrigeração; T5 acondicionamento em embalagem + branqueamento + vácuo + refrigeração.

$\mathrm{O}$ acondicionamento foi realizado em sacos plásticos de polietileno transparente com fechamento hermético (embalagem Zip Lock/26 x17 cm). Para o procedimento de vácuo foi utilizado um aparelho doméstico de sucção (Extrai-ar), a fim de extrair o ar contido no interior das embalagens. Para o processo de branqueamento, as amostras foram mergulhadas em 1,5 litros de água fervente a $100^{\circ} \mathrm{C}$ por dois minutos e, em seguida, resfriadas em 1 litro de água contendo gelo (OLIVEIRA; SANTOS, 2015). Quanto à refrigeração, com exceção da testemunha, os tratamentos foram armazenados em câmara incubadora tipo Biochemical Oxygen Demand (B.O.D., modelo $101 \mathrm{~m} / 2$ ELETROlab) a $8{ }^{\circ} \mathrm{C}$ e umidade relativa de (UR) $85-90 \%$. As testemunhas ficaram dispostas sobre a bancada do laboratório.

Foram realizadas as análises microbiológicas aos 10, 20 e 40 dias de armazenamento, em que para cada etapa quatro repetições foram aleatoriamente amostradas e avaliadas, por tratamento, e os resultados obtidos expressos sob a forma de tabela.

Conforme as Regras para Análise de Sementes (BRASIL, 2009), o preparo das amostras para análise microbiológica se iniciou com a mistura das repetições de cada tratamento em uma única embalagem e, em câmara de fluxo, com o auxílio de uma pinça previamente esterilizada através da flambagem ao rubro em lamparina a álcool, tendo sido retirados dez grãos da mistura, os quais foram postos em duas placas de Petri, contendo meio de cultura B.D.A. (batata, dextrose, ágar), sendo cinco grãos por placa. Depois de tampadas e identificadas, as amostras foram vedadas com filme PVC e dispostas sobre a bancada do laboratório por um período de dez dias, às condições naturais do ambiente, com alternância luminosa de $\pm 12 \mathrm{~h}$ (claro e escuro). Passado esse período, foram realizadas as observações da incidência de bactérias, e a identificação de fungos via microscópio óptico comum, através da observação das estruturas vegetativas e reprodutivas do crescimento dos fitopatógenos em meio de cultura B.D.A., pela observação de preparações microscópicas na presença do corante azul de Amann, e comparação de suas estruturas com base na literatura (MENEZES; OLIVEIRA, 1993; BARNETT; HUNTER, 1998).

\section{Resultados e Discussão}

Para os tratamentos T1, T2 e T3 foram encontradas uma 
maior diversidade de micro-organismos, especialmente, nos primeiros dez dias de armazenamento (Quadro 1). Isso denota que os grãos no início do período de armazenamento possuíram, provavelmente, um alto teor transpiratório, confirmado no ensaio de Kinyuru et al. (2011), elevando o teor de umidade dentro da embalagem zip lock, que não permite trocas com o ambiente externo. Dessa forma, o ambiente mais úmido e produtos frescos favoreceram o desenvolvimento de agentes patogênicos na testemunha (T1) e em tratamentos isolados, que levaram mais tempo que tratamentos associados T4 e T5 para uma estabilização do produto e um ambiente que desfavoreceu o desenvolvimento de micro-organismos no presente estudo pelo baixo número de fungos e bactérias encontrados, quando ocorria associação entre os tratamentos (EL-MOGY; KITINOJA, 2019).

Quadro 1 - Incidência de micro-organismos em amostras de feijão-caupi imaturo em diferentes dias de armazenamento e submetidos aos diferentes tratamentos

\begin{tabular}{|c|c|c|c|}
\hline \multirow{2}{*}{ Tratamento } & \multicolumn{3}{|c|}{ Micro-organismos em dias } \\
\hline & 10 & 20 & 40 \\
\hline $\begin{array}{l}\text { T1 acondicionamento em } \\
\text { embalagem (testemunha) }\end{array}$ & $\begin{array}{l}\text { Aspergillus niger } \\
\text { Aspergillus spp. } \\
\text { Botryodiplodia spp. } \\
\text { Diplodia spp. } \\
\text { Fusarium spp. } \\
\text { Nigrospora spp. } \\
\text { Penicillium spp. }\end{array}$ & $\begin{array}{l}\text { Fusarium spp. } \\
\text { Macrophomina spp. } \\
\text { Nigrospora spp. }\end{array}$ & - \\
\hline $\begin{array}{l}\text { T2 acondicionamento em } \\
\text { embalagem + refrigeração }\end{array}$ & $\begin{array}{c}\text { Aspergillus spp. } \\
\text { Bactéria spp. } \\
\text { Botryodiplodia spp. } \\
\text { Colletotrichum lindemuthianum } \\
\text { Fusarium oxysporum f.sp. } \\
\text { phaseoli } \\
\text { Fusarium spp. } \\
\text { Macrophomina } \text { spp. } \\
\text { Penicillium spp. }\end{array}$ & Bactéria spp. & $\begin{array}{l}\text { Alternaria spp. } \\
\text { Colletotrichum spp. } \\
\text { Fusarium spp. } \\
\text { Geotrichum spp. } \\
\text { Scytalidium spp. }\end{array}$ \\
\hline $\begin{array}{c}\text { T3 acondicionamento em } \\
\text { embalagem + vácuo }+ \\
\text { refrigeração }\end{array}$ & $\begin{array}{c}\text { Aspergillus niger } \\
\text { Colletotrichum spp. } \\
\text { Fusarium oxysporum f.sp. } \\
\text { phaseoli } \\
\text { Geotrichum } \text { spp. } \\
\text { Macrophomina } \text { spp. } \\
\text { Nigrospora spp. } \\
\text { Penicillium } \mathrm{spp} . \\
\text { Rhizopus stolonifer } \\
\end{array}$ & $\begin{array}{l}\text { Aspergillus niger } \\
\text { Fusarium } \text { spp. } \\
\text { Nigrospora } \text { spp. }\end{array}$ & $\begin{array}{l}\text { Fusarium spp. } \\
\text { Nigrospora spp. }\end{array}$ \\
\hline $\begin{array}{c}\text { T4 acondicionamento em } \\
\text { embalagem }+ \text { branqueamento }+ \\
\text { refrigeração }\end{array}$ & \begin{tabular}{|c|} 
Bactéria spp. \\
Colletotrichum lindemuthianum \\
Fusarium spp.
\end{tabular} & Fusarium spp. & $\begin{array}{l}\text { Fusarium spp. } \\
\text { Colletotrichum spp. }\end{array}$ \\
\hline $\begin{array}{c}\text { T5 acondicionamento em } \\
\text { embalagem + branqueamento }+ \\
\text { vácuo }+ \text { refrigeração }\end{array}$ & \begin{tabular}{|c|} 
Aspergillus spp. \\
Colletotrichum lindemuthianum \\
Penicillium spp.
\end{tabular} & $\begin{array}{l}\text { Bactéria spp. } \\
\text { Colletotrichum spp. }\end{array}$ & Bactéria spp. \\
\hline
\end{tabular}

Fonte: Dados da pesquisa.

O decréscimo ou pequeno número de micro-organismos encontrados na testemunha (T1) denota que a mesma não suportou todo o período de avaliação, sendo descartado logo após completar 20 dias, ou seja, o segundo período de avaliação, depois que o experimento foi montado, ocorrendo uma sobreposição de micro-organismos em função do elevado estádio de desenvolvimento pós-colheita.

$\mathrm{O}$ tratamento T2 apresentou um número elevado de microorganismos comparado com os outros tratamentos (T1, T3, T4 e T5) e até mesmo no tratamento T2 com 20 dias. Esse fato pode estar associado a alguns fatores, como: Alternaria spp., apesar de causar doenças sobre o feijão-caupi, são fungos de desenvolvimento mais lento (MENEZES; OLIVEIRA,
1993; AGRIOS, 2005). Em relação ao Geotrichum spp. e Scytalidium spp. esses são contaminantes, que neste caso, podem ter adentrado no material durante o manuseio de avaliações, aproveitando uma porta de entrada proporcionada pelo desenvolvimento de espécies fitopatogênicas sobre o substrato. E por último, não se pode esquecer que se trata de um tratamento isolado, somado a isso se tem o avançado estádio de desenvolvimento dos grãos (AGRIOS, 2005; PIORIBEIRO, ASSIS FILHO, ANDRADE, 2016).

Entre os fungos mais frequentes se observou a presença dos gêneros Aspergillus spp., Fusarium spp. e Penicillium spp. Segundo estudo realizado por Katsurayama e Taniwaki (2017), tais fungos filamentosos produzem micotoxinas, que 
são metabólitos secundários capazes de desencadear doenças no organismo humano e animal, quando ingeridas. Em outro estudo, Prado (2014) relaciona que as micotoxinas de maior importância são: aflatoxinas, produzidas por fungos do gênero Aspergillus; ocratoxinas, produzidas por espécies pertencentes aos gêneros Aspergillus e Penicillium; e desoxinivalenol, fumonisinas e zearalenona, produzidas por várias espécies de fungos do gênero Fusarium. Porém, de acordo com Chavarri et al. (2017), a gravidade e os sintomas de uma micotoxicose variam, consideravelmente, conforme a espécie, a idade, o sexo, o estado nutricional, a dose ingerida, a duração e a repetitividade da exposição.

É importante considerar que os grãos de feijão-caupi imaturos visam, exclusivamente, a alimentação humana, e que, portanto, esses serão submetidos a um processo de cozimento para só então serem consumidos. Contudo, é preciso destacar que, para que ocorra a inativação de algumas micotoxinas, pela sua transformação em compostos nãotóxicos, o tratamento térmico utilizado com auxílio do calor é dependente de algumas variáveis, tais como: nível de contaminação inicial, temperatura de aquecimento, tempo de exposição ao calor, tipo de alimento, além de umidade, $\mathrm{pH}$ e concentração iônica do alimento (CARÃO et al., 2014).

Nos tratamentos T4 e T5, a pouca variedade de microorganismos observada, principalmente, para a primeira etapa de avaliação em comparação as demais no mesmo período, pode estar relacionada ao pré-tratamento de branqueamento empregado nos grãos, visto que esta técnica tem como um dos seus principais objetivos reduzir os micro-organismos presentes no alimento, e com isso reduzir perdas na qualidade do produto durante o período de armazenamento (LEONARDI; AZEVEDO, 2018). Cabe ressaltar que as micotoxinas produzidas por fungos dos gêneros Aspergillus spp., Fusarium spp. e Penicillium spp. apresentam alto ponto de fusão, portanto, não sendo neste caso eficaz o aquecimento como forma de erradicação (GONÇALVES; SANTANA; PELEGRINI, 2017), bem como para as bactérias o processo de branqueamento não é completamente efetivo em sua eliminação (FRANCO; VILLA; COSTA, 2017).

Quanto às bactérias isoladas em T2, T4 e T5, tais microorganismos também são responsáveis por ocasionar doenças em humanos, um exemplo é a Salmonella sp., bactéria entérica, responsável por infecções de origem alimentar grave, decorrentes da ingestão de alimentos contaminados (FERREIRA et al., 2016). Ainda, segundo este autor, tal bactéria é bastante difundida, podendo ser encontrada até mesmo em alimentos de origem vegetal como frutas e vegetais minimamente processados. Em um estudo conduzido por Medeiros, Carvalho e Franco (2017), os mesmos relacionam que entre os mecanismos para prevenção e controle de doenças de transmissões alimentares se constitui como fator de fundamental importância as Boas Práticas de Fabricação (BPF), para que então se possa garantir a segurança e a qualidade dos alimentos, refletindo na saúde do consumidor.
Segundo Cardoso et al. (2017), geralmente, os grãos já vêm do campo contaminados por insetos (e/ou ovos) e microorganismos (e/ou esporos, micélios), e caso as condições de umidade e temperatura se mostrem propícias, esses organismos vão se desenvolver e deteriorar os alimentos. Para evitar que isso aconteça, em alguns casos, são utilizados métodos de conservação como o sistema a vácuo e baixas temperaturas, objetivando reduzir a velocidade das reações químicas e enzimáticas, inibindo o desenvolvimento e a atividade de micro-organismos patógenos e deteriorantes (ROCHA et al., 2014). No entanto, tais procedimentos somente diminuem a intensidade da ação destes organismos, não sendo capazes de paralisá-las totalmente (LEONARDI; AZEVEDO, 2018).

Com relação às demais etapas de avaliação, aos 20 e 40 dias, foi observado que em comparação aos primeiros 10 dias, o tempo de armazenagem resultou em uma diminuição na diversidade de micro-organismos presentes nas amostras, para todos os tratamentos. Porém, não necessariamente em ordem decrescente como pode ser observado em T2 e T4. Tal fato pode estar relacionado aos inúmeros fatores que influenciam no crescimento microbiano, entre esses, as condições de umidade e atividade de água, de temperatura, de $\mathrm{pH}$, de nível de oxigênio, assim como a eficiência dos métodos de conservação empregados (FRANCO; VILLA; COSTA, 2017).

\section{Conclusão}

Entre as condições impostas pelo estudo, o pré-tratamento de branqueamento em T4 e T5 apresenta uma maior redução da diversidade de micro-organismos nos grãos imaturos de feijão-caupi após armazenagem, no entanto, não é capaz de eliminar completamente fungos produtores de micotoxinas e bactérias. O período ideal do ponto de vista de consumo seria de até 10 dias, tendo condições de no máximo 20 dias.

\section{Referências}

AGRIOS, G.N. Plant pathology. Amsterdam: Elsevier Academic Press, 2005.

BARNETT, H. L.; HUNTER, B. B. Illustrated genera of imperfect fungi. Minnesota: The American Phytopathological Society, 1998.

BRASIL. Ministério da Agricultura, Pecuária e Abastecimento. Regras para análise de sementes. Brasília: MAPA, 2009.

CARÃO, A.C.P. et al. Métodos físicos e químicos de detoxificação de aflatoxinas e redução da contaminação fúngica na cadeia produtiva avícola. Ciênc. Rural, v.44, n.4, p. 699-705, 2014.

CARDOSO, M. J. et al. Secagem e armazenamento. In: CARDOSO, M. J. Feijão-caupi: o produtor pergunta, a Embrapa responde. Brasília: Embrapa, 2017. p. 227-235.

CHAVARRI, M. et al. Detección de fusarium verticillioides y fumonisinas en granos de maíz blanco provenientes de los estados Yaracuy y Guárico, Venezuela. Nova Scie., v.9, n. 9, p. 73-184, 2017. doi: 10.21640/ns.v9i19.1035

CONAB - Companhia Nacional de Abastecimento. Acompanhamento da safra brasileira de grãos, v. 6 - Safra 2018/19. Disponível em:<https://www.conab.gov.br/info-agro/ 
safras/graos/boletim-da-safra-de-graos>. Acesso em: 12 abr. 2019.

DE LA VEJA, J. C.; CAÑAREJO, M. A.; PINTO, N. S. Avances en tecnología de atmósferas controladas y sus aplicaciones en la industria. Una revisión. Inform. Tecnol., v.28, n.3, p.75-86, 2017. doi: 10.4067/S0718-07642017000300009

EL-MOGY, M.M.; KITINOJA, L. Review of best postharvest practices for fresh Market green beans. La Pine: The Postharvest Education Foundation, 2019.

FERREIRA, C. C. et al. Análise de coliformes termotolerantes e Salmonella sp. em hortaliças minimamente processadas comercializadas em Belo Horizonte- MG. HU Rev., v.42, n.4, p.307-313, 2016.

FRANCO, S.S.; VILLA, A.A.O; COSTA, J.A.P. Condicionamento de alimentos em câmaras frigorígenas: uma visão técnica. Rev. Cientec, v.9, n.3, p.121-138, 2017.

GONÇALVES, B.; SANTANA, L.; PELEGRINI, P. Micotoxinas: uma revisão sobre as principais doenças desencadeadas no organismo humano e animal. Rev. Saúde Faciplac, v.4, n.1, 2017.

KATSURAYAMA, A.M.; TANIWAKI, M.H. Fungos e aflatoxinas no arroz: ocorrência e significado na saúde do consumidor. Braz. J. Food Technol., v.20, e2017006, 2017. doi: 10.1590/19816723.0617

KINYURU, J.N. et al. Influence of post-harvest handling on the quality of snap bean (Phaseolus vulgaris 1.). J. Agric. Food. Tech., v.1, n.5, p.43-46, 2011.

LEONARDI, J. G.; AZEVEDO, B. M. Métodos de conservação de alimentos. Rev. Saúde Foco, n.10, p.51-61, 2018.

LIMA, R.A.Z.; TOMÉ, L.M.; ABREU, C.M.P. Embalagem a vácuo: efeito no escurecimento e endurecimento do feijão durante o armazenamento. Ciênc. Rural, v.44, n.9, p.664-1670, 2014. doi: $10.1590 / 0103-8478 \mathrm{cr} 20120832$

MEDEIROS, M.G.G.A.; CARVALHO, L.R.; FRANCO, R.M. Percepção sobre a higiene dos manipuladores de alimentos e perfil microbiológico em restaurante universitário. Ciênc. Saúde Coletiva, v.22, n.2, p.383-392, 2017. doi: 10.1590/1413-

\subsection{5}

MELO, N.Q.C. et al. Chemical characterization of green grain before and after thermal processing in biofortified cowpea cultivars. Rev. Ciênc. Agron., v.48, n.5, p.811-816, 2017. doi: 10.5935/1806-6690.20170095

MENDONÇA, C.A. et al. Caracterização fenológica associada a graus-dia em genótipos de feijão-caupi para produção de grãos verdes. Enciclop. Biosfera, v.11, n.21, p.485, 2015.

MENEZES, M.; OLIVEIRA, S.M.A. Fungos fitopatogênicos. Recife: UFRPE, Imprensa Universitária, 1993.

NESPOLO, C.R. et al. Práticas em tecnologia de alimentos. Porto Alegre: Artmed, 2015.

OLIVEIRA, E.N.A.; SANTOS, D.C (Org.). Tecnologia e processamento de frutos e hortaliças. Natal: IFRN, 2015.

PENHA FILHO, N. et al. Estudo sobre a produtividade de feijão caupi "verde" consorciado com milho em função da colheita parcelada das vagens. Agrarian Acad., v. 4, n. 7, p. 246-254, 2017.doi: 10.18677/Agrarian_Academy_2017a24

PIO-RIBEIRO, G.; ASSIS FILHO, F.M.; ANDRADE, G.P. Doenças do feijão-caupi. In: AMORIM, L. et al. Manual de fitopatologia: doenças das plantas cultivadas. Ouro Fino: Editora Agronômica Ceres, 2016.

PRADO, G. Contaminação de alimentos por micotoxinas no Brasil e no mundo. Rev. Saúde Pública do $S U S / M G$, v. 2, n. 2, p. 13-26, 2014.

RINALDI, M.M.; VIEIRA, E.A.; FIALHO, J.F. Conservação pós-colheita de diferentes cultivares de mandioca submetidas ao processamento mínimo e congelamento. Cient,., v.43, n.4, p.287301, 2015. doi: 10.15361/1984-5529.2015v43n4p287-301

ROCHA, P.R.A. et al. Conservação de produtos refrigerados e congelados expostos para a venda em supermercados da cidade de Palmas-TO. J. Bio. Food Scie., v.1, n.2, p.27-31, 2014.

SANTOS, D.P.; LIMA, L.K.S. Avaliação agronômica de variedades de feijão-caupi em cultivo de sequeiro no município de Coremas-PB. Rev. Verde, v.10, n.1, p.218- 222, 2015. doi: 10.18378/rvads.v10i1.2950 